\title{
MAKNA HADAKA MATSURI DI DALAM MASYARAKAT JEPANG DEWASA INI: STUDI KASUS DARI SAIDAIJI EYOU DI OKAYAMA, JEPANG
}

\author{
Frieska Sekar Nadya \\ Japanese Department, Faculty of Language and Culture, Bina Nusantara University, \\ Jln. Kemanggisan Ilir III No.45, Kemanggisan, Jakarta Barat 11480 \\ fnadya@binus.edu
}

\begin{abstract}
Japan has traditional cultures which are still persisted and maintained until now. One of them is matsuri. Matsuri is a religious event which was held by at least one unit of the family to serve kamisama (Gods). One of these events is hadaka matsuri. Hadaka matsuri which still persists till now is Saidaiji Eyou in Okayama. In the Saidaiji Eyou, the participants tried to get the shingi so they can obtain luck during the coming year. Yanagita Kunio defined matsuri into two, matsuri itself and sairei. Sairei is a religious event which was enourmously held and watched by many audiences (Yoneyama Toshinao, 1986:171). Saidaiji Eyou can be categorized as one of sairei form because it is enourmously held, if it is compared with the previous implementation. But, it does not mean that the change of the matsuri into sairei is a decaying point for any religions or cultures in Japan. Oppositely, this change is used as a moment by the Japanese to persist the matsuri itself.
\end{abstract}

Keywords: nudity, matsuri, hadaka, Saidaiji Eyou, sairei

\begin{abstract}
ABSTRAK
Jepang memiliki kebudayaan tradisional yang sampai sekarang masih terus dijaga dan diselenggarakan. Salah satu kebudayaan tradisional tersebut adalah matsuri. Matsuri merupakan suatu kegiatan keagamaan yang diselenggarakan sedikitnya oleh satu unit keluarga untuk melayani kamisama (dewa). Salah satunya adalah hadaka matsuri. Hadaka matsuri yang masih ada hingga sekarang adalah Saidaiji Eyou di Okayama. Dalam Saidaiji Eyou, para peserta berusaha mendapatkan shingi untuk mendapatkan keberuntungan selama setahun mendatang. Yanagita Kunio membedakan matsuri menjadi dua, yaitu matsuri itu sendiri dan sairei. Sairei merupakan kegiatan keagamaan yang diselenggarakan dengan meriah dan disaksikan oleh banyak penonton (Yoneyama Toshinao, 1986:171). Saidaiji Eyou dapat dikatakan sebagai salah satu bentuk sairei karena diselenggarakan dalam bentuk yang besar dan meriah, jika dibandingkan dengan penyelenggaraan awalnya. Akan tetapi, hal ini bukan berarti dengan adanya perubahan matsuri menjadi sairei, merupakan penurunan dalam kebudayaan atau keagamaan di Jepang. Sebaliknya, hal ini dijadikan momen bagi bangsa Jepang untuk mempertahankan budaya matsuri tersebut.
\end{abstract}

Kata kunci: ketelanjangan, matsuri, hadaka, Saidaiji Eyou, sairei 


\section{PENDAHULUAN}

Jepang memiliki kebudayaan tradisional yang sampai sekarang masih terus dijaga dan diselenggarakan. Salah satu kebudayaan tradisional tersebut adalah matsuri. Matsuri merupakan suatu kegiatan keagamaan yang diselenggarakan sedikitnya oleh satu unit keluarga untuk melayani kamisama (dewa), dengan harapan kamisama menjadi tenang, sehingga dapat membawa keberuntungan sepanjang tahun (Nihon Matsuri to Nenchuugyouji Jiten: 418). Sepanjang tahunnya ada banyak matsuri diselenggarakan di seluruh Jepang, seperti yang diungkapkan oleh Yanagita Kunio (Murakami, 1977: 42). Yanagita Kunio juga membedakan matsuri menjadi dua, yaitu matsuri itu sendiri dan sairei. Sairei merupakan kegiatan keagamaan yang diselenggarakan dengan meriah dan disaksikan oleh banyak penonton (Yoneyama Toshinao, 1986:171). Salah satu matsuri yang sering diselenggarakan adalah hadaka matsuri. Seperti matsuri lainnya, hadaka matsuri diselenggarakan di seluruh pelosok negeri Jepang. Hadaka matsuri yang terkenal di antaranya ada di Okayama, yaitu Saidaiji Eyou (Shuukyougaku Jiten 1975: 609). Para peserta Saidaiji Eyou merupakan kaum pria yang hanya memakai fundoshi (cawat) dan sepasang tabi (kaos kaki). Dalam Saidaiji Eyou, para peserta berusaha mendapatkan shingi untuk mendapatkan keberuntungan selama setahun mendatang (The Lit City Museum, 7 Februari 2005).

Dengan adanya interaksi sosial, matsuri menjadi lebih melekat ke dalam hati para pelakunya, baik dalam pelaksanaan maupun konsep yang ada di dalam matsuri itu sendiri. Hal ini tidak hanya tampak saat berlangsungnya hadaka matsuri, melainkan terus berkelanjutan dalam kehidupan keseharian yang dirasakan setiap peserta dalam matsuri, baik dalam housankai (komite pelaksana), sampai ke dalam masyarakat Okayama itu sendiri. Housankai umumnya terdiri dari anggota masyarakat yang berniat melestarikan budaya matsuri, khususnya dalam pembahasan kali ini adalah hadaka matsuri. Kroeber dan Kluckholn dalam Danesi dan Paul Perron (1992:22) menyinggung bahwa kebudayaan merupakan suatu tata cara bila hidup didasari oleh suatu sistem berbagi makna, yang diturunkan dari generasi ke generasi melalui sistem yang sama pula (Danesi dan Paul Perron, 1999:22). Dengan demikian, hadaka matsuri dapat dikatakan sebagai suatu tata cara yang didasari oleh berbagai macam makna, yang diturunkan dari generasi ke generasi hingga sampai saat ini. Selain itu, dijelaskan pula bahwa 'ketelanjangan' merupakan fenomena yang mempresentasikan perilaku, yang dapat menjadi pembeda yang sangat kuat dalam mengidentifikasikan suatu fenomena (Danesi dan Paul Perron, 1999:133). Oleh karena itu, penelitian kali ini di dalam hadaka matsuri bertujuan mempelajari perilaku orang Jepang yang menjadi suatu fenomena di Jepang, yang berbeda dengan budaya yang lain.

\section{Metode Penelitian}

Metode penelitian yang digunakan adalah metode kepustakaan, deskriptif analisis, dan interview (wawancara). Dalam mencari data kepustakaan, diperoleh data dari perpustakaan di Jepang, yaitu di perpustakaan perfektur Okayama di Okayama. Selain itu, datajuga diperoleh dari internet. Wawancara juga dilakukan dengan wakil pendeta utama kuil Saidaiji di kuil Saidaiji untuk mengetahui lebih dalam tentang hadaka matsuri. Setelah data terkumpul, dianalisis, dan ditarik simpulan.

\section{PEMBAHASAN}

\section{Makna Ketelanjangan dalam Hadaka Matsuri}

Kata hadaka dalam bahasa Indonesia dapat diartikan sebagai telanjang atau ketelanjangan. Dalam kamus bahasa Jepang-Indonesia, kata hadaka memiliki definisi: "ketelanjangan; tubuh telanjang; tubuh yang terbuka” (Kenji Matsuura, 1994:235). Akan tetapi, Takahashi dalam Yato Tamotsu (1968), mengungkapkan bahwa di dalam matsuri Jepang, ketelanjangan mempunyai konotasi 
yang lebih luas. Hadaka dapat diartikan sebagai ketelanjangan secara total atau hanya menutupi salah satu bagian tubuh, atau sebagian tubuh yang tidak berbusana (Yato Tamotsu, 1968:149). Hal ini mungkin akan membingungkan, khususnya untuk orang asing. Ketika mendengar kata "hadaka matsuri", yang ada di dalam benak mereka adalah orang-orang yang berpartisipasi dalam matsuri tersebut pasti ‘telanjang bulat', mengikuti definisi kata hadaka yang ada di dalam kamus.

Akan tetapi, ternyata pelaku ritual tidak benar-benar telanjang bulat, mereka masih memakai fundoshi (cawat), kain berwarna putih yang digunakan khusus menutupi alat kelamin pria. Kroeber dan Kluckholn dalam buku Marcel Danesi dan Paul Perron, 1999:132 mengemukakan hubungan 'ketelanjangan' dengan kebudayaan, bahwa ketelanjangan hanya bisa diinterpretasikan secara budaya. Kita semua terlahir 'telanjang', tetapi tak lama kemudian kita mempelajari bahwa ketelanjangan mempunyai konotasi yang negatif. Selain itu, yang dikatakan 'dapat dipertunjukkan' dari bagian tubuh akan berbeda sama sekali pada setiap budaya, karena cara menutupi alat kelamin sebagai batasan dalam lintas budaya juga berbeda. Hal ini yang menyebabkan perbedaan persepsi antara orang Jepang dan orang asing dalam makna telanjang itu sendiri.

\section{Sadaiji Eyou dan Proses Penyucian Diri}

Tatsuo Hagiwara, dalam Yato Tamotsu (1968), mengemukakan bahwa "telanjang atau ketelanjangan” memiliki hubungan dengan matsuri yang ada di Jepang. Hal ini disebabkan karena setiap manusia dilahirkan ke dunia dalam keadaan telanjang dan juga suci. Suci di sini mempunyai makna bebas dari segala dosa, atau belum pernah melakukan kesalahan dan dosa. Oleh karena itu, ketelanjangan dalam upacara-upacara keagamaan dapat dikatakan sebagai upaya untuk mencapai kesucian yang sama, seperti bayi yang terlahir kembali, bersih dan suci, tidak berdosa dan benar-benar alami (Yato Tamotsu, 1968:143). Seperti matsuri-matsuri lainnya, dalam Saidaiji Eyou, sebelum melakukan setiap kegiatan ritual harus melakukan suatu penyucian diri. Hal tersebut memiliki hubungan yang erat kaitannya dengan ke-Tuhanan, atau hal-hal yang bersifat ke-Tuhanan, yaitu kelayakan seseorang untuk dapat bertemu dengan Tuhan. Dalam setiap agama, ketika akan bertemu atau berdoa kepada Tuhan, penganutnya harus melakukan penyucian diri. Hal ini disebabkan di dalam masyarakat, terutama penganut kepercayaan ataupun agama, Tuhan mempunyai suatu persepsi akan kesucian yang lebih tinggi daripada manusia.

Menurut Ishikawa (1986), dikarenakan kamigami mengutamakan kesucian dibandingkan hal lainnya, maka masyarakat Jepang harus menyucikan pikiran dan badan sebelum dapat menerima kedatangan kamigami pada ritual. Oleh karena itu, selama waktu tertentu sebelum pelaksanaan ritual, mereka hidup dalam kesucian (imi) untuk menghindari ketidaksucian (kegare). Ketidaksucian (kegare) terdiri atas tiga jenis, yaitu yang berhubungan dengan kematian, darah, dan selain kedua hal tersebut. Contoh hal yang berhubungan dengan kematian adalah ketika seseorang yang merupakan keluarga dari yang ditinggalkan, maka sebelum periode berkabung selesai, ia mempunyai kegare yang dapat mempengaruhi orang-orang yang ada di sekitarnya. Sedangkan yang berhubungan dengan darah, misalnya mempunyai luka, mendapat haid, habis melahirkan, atau terkena darah hewan, dan lain sebagainya. Sementara itu, kegare yang disebabkan selain kematian dan darah, misalnya karena adanya wabah penyakit, bencana, atau kejadian yang merugikan, termasuk menyebutkan kata yang berhubungan dengan kegare tersebut. Sebagai contoh, ketika seseorang menyebutkan kata haka atau "kuburan", maka dirinya dan orang yang mendengar kata tersebut mendapatkan kegare. Suatu pantangan bagi orang Jepang menyebutkan kata seperti itu di tengah-tengah kehadiran kami (Ishikawa Takashi, 1986:103-105).

Dalam kepercayaan Shinto, juga diungkapkan mengapa peserta yang berpartisipasi dalam matsuri pada umumnya adalah laki-laki. Hal ini disebabkan karena perempuan lebih mudah mendapatkan ketidaksucian yang disebabkan oleh darah. Ada beberapa matsuri bahkan tidak memperbolehkan perempuan untuk berpartisipasi sama sekali. Hal ini bukan disebabkan adanya kepercayaan untuk merendahkan martabat seorang perempuan, melainkan dikarenakan kerentanan 
mereka pada kegare yang disebabkan oleh darah. Shinto tidak mendiskriminasikan atau merendahkan status mereka sebagai perempuan, akan tetapi karena kegare yang disebabkan oleh darah tersebut (Ishikawa Takashi, 1986:105). Oleh karena itu, dalam perayaan matsuri, setiap peserta harus melakukan penyucian diri terlebih dahulu. Walaupun dalam keadaan hanya memakai fundoshi, setiap peserta harus tetap melakukan penyucian diri.

Dalam kepercayaan Shinto, ada beberapa cara penyucian diri yang dapat dilakukan oleh pendeta atau oleh penganut kepercayaannya sendiri (peserta matsuri). Penyucian diri yang secara simbolis dilakukan dengan berkumur-kumur dan mencuci tangan dengan air bersih ketika masuk kuil disebut sebagai temizu. Penyucian diri secara formal yang dilakukan oleh pendeta dengan membacakan doa-doa penyucian atau sutra-sutra Budha, sembari menggerak-gerakkan tongkat penyucian di depan para penganutnya disebut harae. Seringkali pula proses harae ini disertai dengan memercikkan garam atau air garam (air laut). Sementara itu, penyucian diri dengan melakukan mandi disebut sebagai misogi (Ono Sokyo, 1993:51-52).

Begitu pula dengan makna ketelanjangan di dalam matsuri yang juga merupakan upaya mencapai kesucian. Seperti yang terkutip di dalam Nihon Minzoku Shuukyou Jiten (2000: 461), bahwa Orang-orang dari kelompok tertentu datang berkunjung ke kuil dengan telanjang, sambil melaksanakan ritual pembersihan. Hal ini banyak terlihat sehubungan dengan Shuushoe dari tahun baru. Selain itu, adapula yang seringkali diselenggarakan pada musim panas. Walaupun pada umumnya menjadi telanjang memiliki makna penyucian diri sesuai pelaksanaan matsuri (sairei), tetapi pada generasi berikutnya seperti diletakkan atau dipusatkan pada keadaan menjadi telanjang, yang disebut sebagai hadaka matsuri. Hal menjadi telanjang, di negeri Jepang sering pula dinyatakan sebagai salah satu bentuk secara representatif untuk memohonkan dikabulkannya doa-doa yang disampaikan. Hal ini disebabkan karena dengan tercapainya kesucian, diharapkan segala doa-doa yang telah dipanjatkan dapat dikabulkan semua. Hal ini pula yang diharapkan para peserta Saidaiji Eyou untuk memulai lembaran baru di dalam kehidupan, yang lebih dihargai oleh kami-gami, sehingga segala macam keberuntungan datang berlimpah.

\section{Penyelenggaraan Sadaiji Eyou}

Dalam penyelenggaraan Saidaiji Eyou sendiri, ada beberapa tempat yang harus dilalui oleh pesertanya. Berikut ini adalah rute yang harus diikuti oleh peserta Saidaiji Eyou. Pertama, para peserta harus masuk melalui niou mon (gerbang dua tingkat). Gerbang ini sebagai tanda pemisah antara dua daerah atau dunia yang akan dimasuki oleh peserta, yaitu daerah duniawi (kehidupan manusia) dan dunia dewa. Dengan melewati gerbang ini, diharapkan dapat disadari bahwa mereka sedang memasuki daerah yang disucikan karena merupakan tempat tinggal para dewa. Maka dari itu, niou mon juga disebut dengan gerbang dewa.

Kedua, mereka harus melewati ishi mon (gerbang batu) untuk melakukan penyucian diri di koritoriba. Seperti halnya niou mon, ishi mon merupakan pemisah antara dua daerah, yaitu daerah penyucian diri dan tempat tinggal dewa tersebut.

Ketiga, para peserta harus membersihkan atau menyucikan diri di koritoriba (sebuah kolam tempat untuk menyucikan diri). Adapun media yang digunakan untuk penyucian diri adalah air karena air dipercaya dapat menyucikan diri. Membersihkan diri bukan berarti harus mandi. Di koritoriba, para peserta hanya harus memutari pancuran air dengan arah yang benar, yaitu dari kanan ke kiri.

Keempat, setelah melakukan penyucian diri, para peserta harus melanjutkan ritualnya dengan berdoa di aula kuil utama (hondou ooyuka) yang luas, yaitu berdiri di depan altar, menepukkan kedua belah tangan sebanyak dua kali, kemudian memanjatkan doa kepada dewa. 
Kelima, setelah berdoa di hondou, dilanjutkan dengan mengunjungi tempat lahirnya Go-ou, yaitu chinjudou. Di tempat ini, para peserta kembali melakukan ritual penghormatan kepada Goou (berdoa). Akan tetapi, di tempat ini doanya lebih dikhususkan kepada Go-ou karena shingi yang akan diperebutkan nanti, yang dipercaya membawakan keberuntungan, merupakan bagian dari kebaikhatian Go-ou tersebut.

Keenam, para peserta berkumpul dan harus melewati Yonponjuu atau empat buah pilar. Yonponjuu, yang menyerupai ring ini, dihubungkan dengan nawa. Yonponjuu merupakan tempat untuk mengumpulkan energi positif, sehingga pada dewa yang ada dalam hondou juga berada di dalam yonponjuu ini. Dengan demikian, sebenarnya dengan melewati yonponjuu ini secara keagamaan tujuan Saidaiji Eyou telah ada dalamnya, tidak perlu sampai menunggu shingi. Adapula yang mengartikan bahwa dengan melewati yonponjuu ini, segala energi negatif (ketidakberuntungan) menjadi nol (Miura, 1985:20).

Ketujuh atau terakhir, para peserta harus kembali mengunjungi hondou untuk mengikuti ritual terakhir, yaitu menunggu pelemparan shingi. Tepat pada pukul 12.00 (tengah malam), shingi dilempar dari gofukumado (jendela yang berada di bagian atas di dalam hondou oleh ketua pendeta). Saat pelemparan akan dimulai, seluruh lampu di hondou dipadamkan dan terdengar genderang dipukul tiga kali. Pada pukulan ketiga, shingi dilemparkan ke para peserta Saidaiji Eyou yang telah menunggu di aula kuil utama (hondou ooyuka). Setelah shingi dilempar, perlahan-lahan lampu dinyalakan kembali. Maka, perebutan shingi pun dimulai. Para peserta yang merupakan gabungan dari beberapa kelompok masyarakat berjuang untuk mendapatkan shingi. Saling dorong pun tidak terelakkan lagi. Tidak jarang banyak yang terluka pada saat merebutkan shingi ini.

Peserta yang bisa menangkap shingi harus dapat membawa shingi tersebut keluar dari kuil Saidaiji menuju salah satu dari rumah penduduk yang telah dipilih oleh kuil Saidaiji. Tandanya adalah di depan rumah tersebut dipasang sebuah lampion berwarna putih. Peserta yang membawa shingi tersebut harus masuk ke rumah tersebut dan meletakkan shingi pada sebuah wadah berisi beras putih yang sudah disiapkan oleh tuan rumah. Kemudian, salah satu wakil dari rumah yang beruntung tersebut akan datang ke kuil Saidaiji dan mengabarkannya kepada pendeta utama. Pendeta utama kemudian datang untuk memastikan bahwa shingi tersebut adalah shingi yang asli. Apabila kedua shingi sudah ditangkap, maka akan diumumkan di kuil Saidaiji. Dengan demikian, berakhirlah Saidaiji Eyou.

Keesokan harinya, kedua tuan rumah yang kedapatan shingi akan mengembalikan shingi ke kuil Saidaiji, mengadakan makan bersama dengan peserta yang telah membawa shingi ke rumah mereka. Dengan kata lain, peserta yang membawa shingi ke rumah mereka telah membawa keberuntungan untuk rumah itu sendiri. Setelah itu, pendeta akan menyerahkan uang dan barang seserahan (yang diterima kuil Saidaiji selama Saidaiji Eyou berlangsung) kepada peserta yang berhasil menangkap shingi tersebut (YatoTamotsu, 1968:165).

\section{Budha dan Shinto dalam Saidaji Eyou}

Menurut Hori (1983), agama Budha dan kepercayaan Shinto mempunyai keterkaitan satu sama lainnya. Agama Budha mengalami transformasi dalam berbagai cara, selama perjalanan yang jauh dari India ke Korea melalui Asia Tengah dan China. Agama Budha datang ke Jepang pada pertengahan abad keenam di bawah pengawasan keluarga bangsawan dan kerajaan, serta kelompok tertentu. Elemen-elemen religius, magis dan etis yang dipinjam tersebut terasimilasi, diinterpretasikan, dan disistemasi kembali ke dalam kepercayaan bangsa Jepang sebagai suatu kesatuan, melalui kontak dan pertukaran budaya, baik dengan berbagai tradisi, ritual, dan kepercayaan dari Shinto (Hori Ichiro, 1983:10).

Lebih jauh lagi diungkapkan bahwa dalam perkembangan ajaran agama Budha, untuk memudahkan diterimanya agama tersebut dilakukan penggabungan dengan kepercayaan yang sudah melekat dalam masyarakat, yaitu Shinto. Ketika agama Budha masuk ke dalam komunitas lokal, para 
pendeta Budha harus menyesuaikan ajarannya dengan orang lokal dan dewa (kami) dalam komunitas tersebut. Sebagai hasil dari penyesuaian tersebut, suatu kuil Budha yang khusus dibangun di dalam komplek, pada hampir semua kuil Shinto dan didedikasikan untuk kami Shinto pada kuil tersebut, yang disebut sebagai Jinguu-ji. Sebaliknya, ada kami Shinto yang dibangun kuilnya di dalam setiap komplek kuil Budha, yang disembah oleh pendeta Budha dengan tatanan agama Budha (Hori Ichiro, 1983:37-38).

Dengan demikian, walaupun kuil Saidaiji merupakan kuil Budha karena digunakan untuk menyembah dewa Budha, Senjukannonbosatsu, akan tetapi dengan dibangunnya chinjudou dalam kompleks kuil Sadaiji, Go-ousho Daigongen dan Konpira Daigongen, yang merupakan kami pelindung kota Okayama juga dapat disembah di kuil ini. Demikian halnya di dalam Saidaji Eyou, yang merupakan salah satu ritual dalam kepercayaan Shinto. Baik konsep penyelenggaraan matsuri maupun konsep harae (penyucian diri) dan kegare merupakan konsep-konsep yang berkaitan dengan kepercayaan Shinto. Akan tetapi, pendeta yang memimpin penyelenggaraan Saidaiji Eyou merupakan pendeta Budha, ataupun doa-doa yang dibacakan selama Shuushoe merupakan sutra-sutra Budha. Bahkan, shingi yang digunakan dalam Saidaiji Eyou merupakan pengganti Go-ou fuda, yang berisikan doa-doa kepada Go-ou sama. Kemudian, dalam rute yang harus dilalui peserta Saidaiji Eyou, ada kewajiban untuk berdoa di chinjudou sebagai penghormatan kepada Go-ou sama. Hal ini menunjukkan bahwa Saidaiji Eyou tidak bisa lepas akan kedua unsur ini, baik agama Budha maupun kepercayaan Shinto.

\section{Sairei dan Hadaka Matsuri dalam Hubungan Sosial}

Di dalam buku bertajuk “Toshi to Matsuri no Jinruigaku”, dijelaskan bahwa terdapat dua jenis matsuri, seperti halnya Yanagita Kunio telah membedakan sairei dan matsuri. Dengan kata lain, perintis besar dalam ilmu masyarakat Jepang ini menjelaskan bahwa matsuri merupakan kegiatan melayani arwah leluhur. Sementara itu, kegiatan melayani arwah leluhur yang diselenggarakan secara umum dan berkelompok, disertai dengan kemeriahan dan penambahan peserta yang menyaksikan acara tersebut, yang disebut sebagai sairei (Yoneyama Toshinao, 1986:171). Matsuri yang diselenggarakan sesuai dengan kepercayaan atau kebiasaan di dalam kelompok tertentu, tanpa suatu kemeriahan dan hanya memusatkan pada kekhidmatan penyelenggaraannya, merupakan matsuri yang sesungguhnya. Sementara itu, sairei merupakan kegiatan keagamaan yang diselenggarakan dengan meriah dan disaksikan oleh banyak penonton. Dengan kata lain, sairei merupakan suatu perluasan makna dari matsuri. Dari bentuk yang sederhana, yang hanya diikuti beberapa orang, menjadi bentuk yang lebih meriah dan disaksikan banyak orang.

Seiring dengan perkembangan desa menjadi kota, maka sedikit banyak hal ini membawa pengaruh pada pelaksanaan maupun tujuan dari matsuri itu sendiri. Matsuri yang dilaksanakan di desa pada umumnya lebih khidmat dan berpusat pada ritual yang berhubungan dengan pertanian, sehingga lebih ditekankan pada hubungan antara manusia dengan kami. Sementara itu, matsuri yang dilaksanakan di kota bertujuan untuk mengusir atau menghindarkan diri dari bala bencana dan atau wabah penyakit, seperti yang diungkapkan bahwa di dalam Matsuri Jepang ada yang disebut sebagai hadaka matsuri secara khusus. Yang terkenal di antaranya adalah Saidaiji di prefektur Okayama, Konomiya di prefektur Aichi, Kuroishitera di kota Mizudoro prefektur Iwate, beribu-ribu pemuda telanjang datang beramai-ramai untuk bertemu dengan penguasa dan dewanya. Hal ini merupakan interpretasi dari suatu kepercayaan popular dalam masyarakat yang tidak begitu berlebihan, yang disebut sebagai usaha mencegah malapetaka (Shuukyou Gaku Jiten, 1975:609).

Akan tetapi, dengan semakin sedikitnya hubungan sosial dalam perkotaan, maka kegiatan dalam matsuri seringkali digunakan pesertanya sebagai ajang bersosialisasi. Oleh karena itu, rasa kesetiakawanan para pendukung matsuri juga memegang peran yang penting dalam penyelenggaraannya. Demikian pula dalam Saidaiji Eyou, selain peserta mengharapkan keberuntungan dan terhindar dari segala bencana, mereka juga melakukan kegiatan sosialisasi. Sebagai mahluk sosial, 
manusia tidak bisa hidup sendirian. Manusia akan selalu bergantung pada manusia lain, dan hal ini diperlihatkan dalam Saidaiji Eyou. Para peserta Saidaiji Eyou merupakan kumpulan dari berbagai kelompok masyarakat, dari pengusaha, petani, maupun pelajar, baik orang Jepang maupun orang asing. Dalam kelompok tersebut, mereka saling melindungi dan berusaha bersama untuk saling menghangatkan badan di dalam dinginnya malam pada bulan Februari. Selain itu juga, dalam upaya menangkap Shingi, diperlukan kerjasama kelompok yang baik. Terbukti dari hasil wawancara dengan wakil ketua pendeta kuil Saidaiji, bahwa pemenang (yang berhasil menangkap shingi) merupakan kelompok yang rajin. Sebelum Saidaiji Eyou berlangsung, mereka banyak berlatih, berpantang makan daging (hanya makan sayur-sayuran), serta sering datang ke kuil untuk berdoa.

Selain itu, Saidaiji Eyou juga dapat dikatakan sebagai salah satu bentuk sairei karena diselenggarakan dalam bentuk yang lebih besar dan meriah, jika dibandingkan dengan penyelenggaraan awalnya, yang menjadi tempat bersosialisasi antar pesertanya. Pada awalnya, pendeta kuil Saidaiji hanya bertujuan untuk membagikan kertas jimat (ofuda) bagi orang yang datang untuk berdoa di kuil Saidaiji. Namun, sekarang sudah banyak tambahan aspek festivalnya, seperti adanya komite panitia penyelenggara (Saidaiji Housankai). Juga terdapat tiga jenis tempat menonton; berdasarkan biayanya, yaitu tempat menonton seharga 500, 1000, dan 5000 yen. Tiket dengan harga 500 yen, penonton tidak mendapatkan tempat duduk (berdiri) dan lokasinya jauh dari hondo. Tiket seharga 1000 yen juga tidak mendapatkan tempat duduk, tetapi lokasinya cukup dekat dengan hondo (tepat di belakang tempat menonton seharga 5000 yen). Sementara itu, tiket seharga 5000 yen mendapatkan tempat duduk dan lokasinya yang berdekatan dengan hondo.

Selain itu, untuk memeriahkan Saidaiji Eyou, kota Okayama juga ikut berbenah, yaitu menghias kotanya dengan pernak-pernik lampion, spanduk, sampai dengan gambar yang berhubungan dengan Sadaiji Eyou tersebut. Hal ini sudah terlihat ketika turun dari stasiun Saidaiji. Di sepanjang jalan terlihat lampion dan spanduk bertuliskan hadaka matsuri. Bahkan, terdapat pintu rumah penduduk yang dihiasi dengan gambar kemeriahan Saidaiji Eyou. Kemudian, di sepanjang jalan menuju kuil Saidaiji terdapat deretan yatai. Terdapat pula sebuah papan yang menggambarkan perjuangan peserta saat memperebutkan shingi. Selain itu, Saidaiji Eyou juga dimasukkan ke dalam pamflet-pamflet pariwisata Okayama, sehingga sebagai salah satu daya tarik wisatawan, baik lokal maupun asing untuk datang ke Okayama.

\section{Internasionalisasi Saidaiji Eyou}

Seperti yang sudah sedikit diuraikan sebelumnya, Saidaiji Eyou selain sebagai daya tarik Okayama, namun juga sebagai daya tarik dalam memperkenalkan salah satu kebudayaan Jepang kuno yang masih ada hingga saat ini kepada orang asing. Hal ini berhasil, terbukti dengan peserta Saidaiji Eyou bukan hanya dari penduduk kota Okayama, ataupun dari warga negara Jepang saja, melainkan ada pula yang berasal dari luar negeri. Sebenarnya Saidaiji Eyou ini sudah terkenal di luar negeri sejak dulu. Pada tahun 1953 (Showa 28), foto Saidaiji Eyou pernah masuk majalah LIFE terbitan Amerika. Kemudian, foto Saidaiji Eyou juga diperkenalkan oleh penerbit Graff ke Inggris, Perancis, Italia, Swedia, Norwegia, dan negara-negara Eropa lainnya. Selain itu, pada tahun 1961, Saidaiji Eyou masuk dalam film Italia yang berjudul Zokusekai no yoru (Miura Kanou, 1985:27). Hal inilah yang menjadi salah satu alasan banyaknya orang asing yang ingin ikut berpartisipasi dalam Saidaiji Eyou. Selain itu, Saidaiji Eyou juga diliput secara langsung, baik oleh stasiun TV lokal maupun asing. Di dalam Saidaiji Eyou tahun 2006, terdapat reporter beserta cameramen dari stasiun TV Jerman untuk meliput secara langsung (Sanyou Shinbun, 2006:34). Kemudian, masih pada tahun yang sama, saat Saidaiji Eyou berlangsung, terdapat satu acara tambahan yang tidak tercantum dalam jadwal, yaitu tarian samba dari Brasil. Berdasarkan hasil wawancara, tarian samba tersebut untuk menyemangati peserta Saidaiji Eyou yang berasal dari Brazil. 


\section{Originalitas di Tengah Perubahan}

Adanya perubahan matsuri menjadi sairei bukan merupakan suatu penurunan dalam kebudayaan atau keagamaan di Jepang. Sebaliknya, hal ini dijadikan momen bagi bangsa Jepang untuk mempertahankan budaya matsuri tersebut. Hal yang sama juga diungkapkan Michael Ashenazi, bahwa secara umum ia setuju dengan bertambahnya populitas pada era modern, sedikit banyak telah mempengaruhi perubahan badan religius yang tradisional. Selain itu, secara tidak langsung mempengaruhi kelangsungan Matsuri itu sendiri. Akan tetapi, ia tidak mendukung pendapat Morioka yang mengemukakan bahwa kepercayaan Shinto telah memudar. Perubahan dalam Matsuri tidak bisa dipandang sebagai penurunan yang sederhana, baik dari kepercayaan Shinto ataupun penyelenggaraan Matsuri itu sendiri (Michael Ashenazi, 1993:11). Lebih jauh lagi, Michael Ashkenazi juga mengungkapkan bahwa data dan analisis yang ia lakukan menunjukkan bahwa Matsuri dapat bertahan terhadap perkembangan atau perubahan yang terjadi di dalam masyarakat, karena matsuri ikut membantu komunitas di sekitarnya mempertahankan kelangsungan komunitas tersebut. Sisi yang tidak baik dari pandangan tersebut mengakibatkan hubungan tersebut jatuh ke dalam interpretasi secara fungsional, yaitu keberadaan Matsuri terlihat hanya sebagai alat dalam strategi mempertahankan keberlangsung hidup dari komunitas bangsa Jepang. Peneliti lain, Sonoda, juga mencatat bahwa matsuri dapat bertahan karena matsuri merupakan ekspresi dan sarana dari ungkapan kebudayaan yang dikenal umum dalam masyarakat (Michael Ashenazi, 1993:146-147).

Sebagai contoh, alasan Saidaiji Eyou hanya dilakukan pada saat musim dingin adalah karena Saidaiji Eyou merupakan kelanjutan dari ritual keagamaan oshogatsu, yaitu perayaan tahun baru. Hal ini merupakan dorongan bagi masyarakat Jepang untuk memulai lembaran hidup baru yang lebih baik pada setiap tahun baru. Udara yang dingin merupakan wujud tantangan untuk memulai hal tersebut. Penyucian diri, kembali ke situasi ketika masih baru lahir ke dunia merupakan harapan untuk mendapatkan kehidupan yang baru dan lebih baik lagi. Nilai-nilai keagamaan seperti ini yang masih dipertahankan; yang kemudian mengundang ketertarikan bagi orang-orang asing untuk menyaksikan, merasakan, seperti apa bergelut dengan udara dingin, hanya dengan menggunakan fundoshi atau cawat, memperebutkan shingi, sehingga dapat memulai hidup baru yang lebih baik untuk setahun kedepan. Hal ini membuktikan walaupun Sadaiji Eyou telah berkembang menjadi sairei, tetapi tetap mempertahankan nilai-nilai yang menjadi dasar atau pondasi dari penyelenggaraan matsuri itu sendiri. Dengan demikian, walaupun ada perubahan pola masyarakat dari pedesaan menjadi perkotaan, atau perubahan dari matsuri menjadi sairei, inti dari matsuri itu sendiri tetap bertahan hingga sekarang. Bukan hanya sebagai alat bagi masyarakat Jepang untuk mempertahankan komunitasnya, tetapi ada banyak unsur-unsur lain yang mendukung, yang membuat matsuri dapat bertahan di tengah perubahan tersebut.

\section{PENUTUP}

Hadaka matsuri mempunyai makna yang lebih luas daripada makna telanjang yang sesungguhnya. Setiap negara tentu punya makna telanjang dalam setiap budaya atau kehidupan sosialnya. Di Indonesia misalnya, yang sebagian besar beragama Islam, tentu memiliki makna ketelanjangan yang berbeda dengan negara Amerika, yang lebih bersifat moderat. Di dalam hadaka matsuri, makna telanjang bukan berarti sepenuhnya tidak berpakaian, melainkan masih menggunakan fundoshi atau cawat. Selain itu, makna telanjang di dalam hadaka matsuri lebih dititikberatkan pada pengertian proses kembali suci dan bersih seperti anak yang baru lahir ke dunia.

Hadaka matsuri walaupun seperti yang telah dibahas mengalami perubahan dari matsuri menjadi sairei, yang lebih mementingkan kemeriahan penyelenggaraannya (maknanya lebih mendekati suatu festival). Akan tetapi, inti dari penyelenggaraan matsuri tersebut, terutama nilai-nilai keagamaannya masih bertahan hingga sekarang. Hal ini disebabkan, seperti yang telah diungkapkan 
Michael Ashkenazi, karena matsuri merupakan media bagi masyarakat Jepang mempertahankan komunitasnya. Dengan kata lain, Sadaiji Eyou merupakan hadaka matsuri yang memiliki ikatan kebersamaan sosial yang sangat kuat. Walaupun Saidaiji Eyou telah menjadi sairei, tetapi masih melaksanakan ritualnya secara serius. Hal-hal inilah yang membuat Saidaiji Eyou berbeda dengan yang lainnya. Di dalam masyarakat Jepang dewasa ini, Saidaiji Eyou di Okayama, yang tiap tahun bertambah jumlah pesertanya, masih dapat menampilkan salah satu kebudayaan Jepang yang unik dan masih eksis dari dulu hingga sekarang.

\section{DAFTAR PUSTAKA}

Ashkenazi, M. (1993). Matsuri: Festivals of a Japanese Town. Honolulu: University of Hawaii Press.

Danesi, M. (1999). Analyzing Culture: An Introduction and Handbook. Indiana: Indiana University Press.

Hori, I. (1983). Folk Religion in Japan: Continuity and Change edited by Kitagawa Joseph. Chicago: Midway, the University of Chicago Press.

Ishikawa, T. (1986). Kokoro: The Soul of Japan. Tokyo: The East Publications, Inc.

Miura, K. (1985). Okayama no Eyou. Okayama: Nihon Bunkyo.

Murakami, T. (1977). Nihon Bunka Teiyo. (Ed.). Tokyo: Nihon Bunka Kenkyu Jyohen.

Ono, S. (1993). Shinto: The Kami Way, cetakan ke-24. Japan: Charles E. Turtle Company.

Ross, F.H. (1965). Shinto: The Way of Japan. Boston: Beacon Press.

Yato, T. (1968). Naked Festivals of Japan. Tokyo: John Weatherhill Inc.

Yoneyama, T. (1986). Toshi to Matsuri no Jinruigaku. Tokyo: Kawada Shobou Shinsha. 


\section{LAMPIRAN}

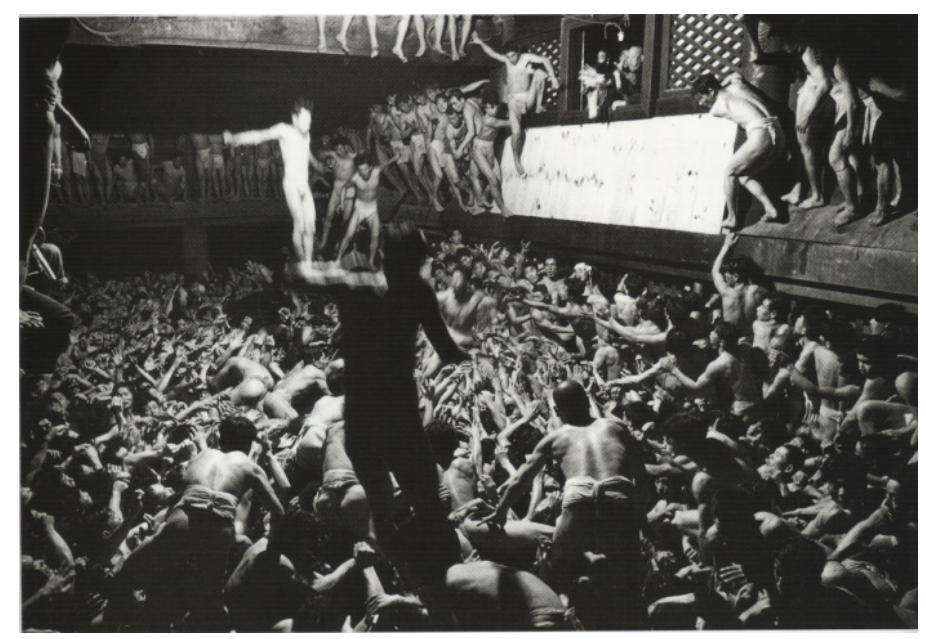

Gambar 1 Suasana di hondou saat pelemparan shingi (Midorikawa Youichi, 2002)

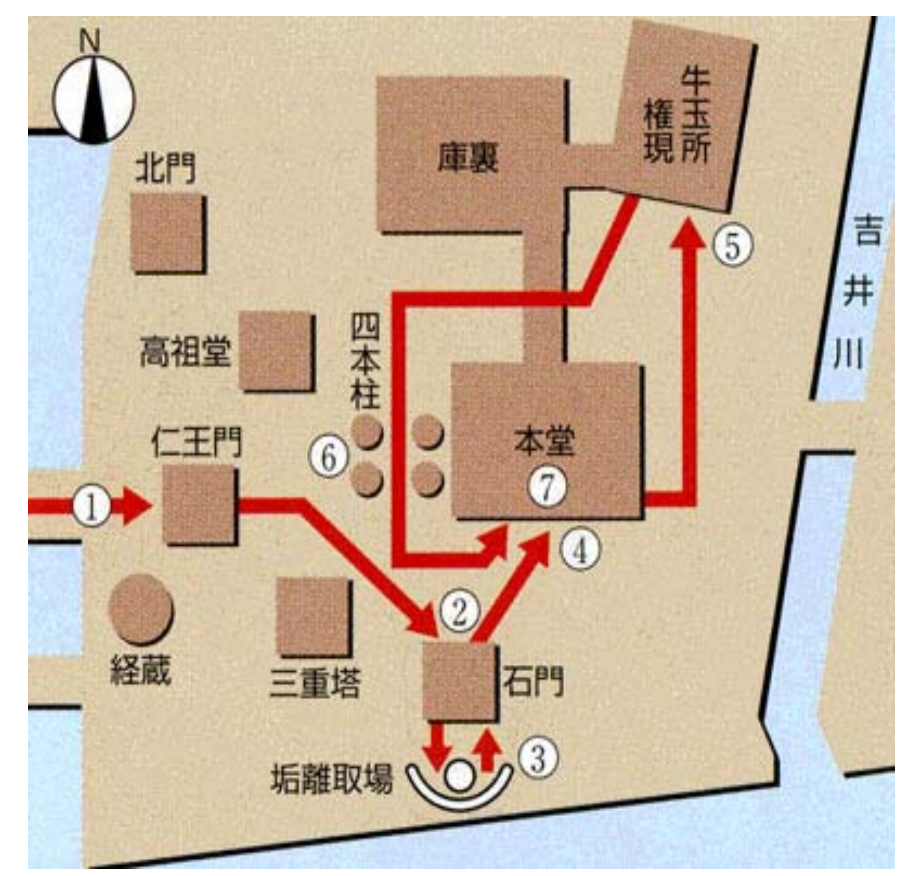

Gambar 2 Rute yang harus dilewati peserta Eyou, (1) melewati niou mon; (2) melewati ishi mon; (3) menyucikan diri di koritoriba; (4) berdoa di hondou; (5) berziarah Goou di chinjudo; (6) berkumpul dan melewati yonponjuu;

(7)berkumpul di hondou lagi untuk memperebutkan shingi (Yoshio Wada, 2005). 